\title{
Enamel properties after tooth bleaching with hydrogen/ carbamide peroxides in association with a CPP-ACP paste
}

\author{
ADRIANA ALCANTARA MEIRA DE VASCONCELOS ${ }^{1}$, ANA GABRIELA GAMA CUNHA ${ }^{1}$, \\ BONIEK CASTILLO DUTRA BORGES ${ }^{1}$, JUSSIER DE OLIVEIRA VITORIANO ${ }^{2}$, \\ CLODOMIRO ALVES-JÚNIOR ${ }^{2}$, CLÁUDIA TAVARES MACHADO ${ }^{1}$ \& \\ ALEX JOSÉ SOUZA DOS SANTOS ${ }^{1}$
}

\author{
${ }^{1}$ School of Dentistry, Potiguar University (Laureate International Universities), Natal, Brazil, and ${ }^{2}$ Department of \\ Theoretical and Experimental Physics, Plasmas and Processes Laboratory (LABPLASMA), Federal University of Rio \\ Grande do Norte, Natal, Brazil
}

\begin{abstract}
Background. This study evaluated the impact of bleaching teeth using blends of a CPP-ACP paste (MI Paste; MI) and carbamide/hydrogen peroxides in different proportions on surface properties of bleached enamel. Methods. Ninety bovine incisors were bleached with $7.5 \%$ hydrogen peroxide (HP), 16\% carbamide peroxide (CP), MI and blends of $\mathrm{HP}$ or CP:MI at three proportions $(1: 1,2: 1,1: 2)$. Hardness and roughness were measured at baseline and after bleaching. Enamel morphology was evaluated by Scanning Electron Microscopy (SEM). The data were analyzed by two-way ANOVA for repeated measurements and Tukey's test. Results. Most of the samples bleached with MI in combination with peroxides presented increased hardness and roughness which were associated to mineral deposition, as observed by SEM images. Blends with higher fractions of MI did not offer superior benefits. Conclusions. The use of a CPP-ACP paste mixed to carbamide/ hydrogen peroxides can decrease adverse side-effects from tooth bleaching on an enamel surface.
\end{abstract}

Key Words: hardness, roughness, scanning electron microscopy, morphology

\section{Introduction}

Hydrogen or carbamide peroxides are the most commonly used agents for vital tooth bleaching. The efficacy of low concentration bleaching peroxides used in the at-home regimen has already been established [1]. However, side-effects on enamel such as hardness decrease, increased roughness and morphologic alterations resulting from mineral loss remain quite a debatable topic in the literature due to different results found elsewhere $[2,3]$. In fact, it has been evidenced that low concentration bleaching peroxides can change calcium and phosphate mineral content of bleached enamel [4].

Recently, a new calcium phosphate remineralization technology has been developed based on casein phosphopeptide-amorphous calcium phosphate (CPP-ACP) (Recaldent ${ }^{\mathrm{TM}}$ CASRN691364-49-5). The developers of this product claim that the CPP stabilizes high concentrations of calcium and phosphate ions, together with fluoride ions, at the tooth surface by binding to pellicle and plaque [5]. This nanocomplex acts as a calcium and phosphate reservoir that attaches itself to dental plaque and tooth surfaces. On acid challenge, the attached CPP$\mathrm{ACP}$ releases calcium and phosphate ions, thus maintaining a supersaturated mineral environment and thereby reducing demineralization and enhancing remineralization of enamel, as observed in some clinical in situ studies [6]. The use of CPP-ACP along with bleaching peroxides might enhance the remineralization of the enamel in contact with the agent by providing calcium and phosphate ions.

Results obtained elsewhere [7] evidenced that the association of a CPP-ACP paste (MI Paste, GC Corporation, Tokyo, Japan) with bleaching peroxides mixed in a similar proportion recovered mineral loss by increased enamel microhardness of bleached

Correspondence: Boniek, Castillo Dutra Borges, School of Dentistry, Potiguar University (Laureate International Universities), Av. Senador Salgado Filho, 1610, zip-code: 59.056-000, Natal, RN, Brazil. Tel: +55 843215 1230. Fax: +55 843215 1230. E-mail: boniek.castillo@gmail.com 
Table I. Materials used in this study.

\begin{tabular}{|c|c|c|}
\hline Commercial brand and manufacturer & Batch number & Chemical composition \\
\hline $\begin{array}{l}\text { White Class with Calcium (FGM Dental } \\
\text { Products, Joinville, SC, Brazil) }\end{array}$ & $178 / 10$ & $\begin{array}{l}\text { 7.5\% hydrogen peroxide gel, neutralized carbopol, potassium } \\
\text { nitrate, sodium fluoride, aloe vera, calcium gluconate, } \\
\text { stabilizer, deionized water, surfactant }\end{array}$ \\
\hline $\begin{array}{l}\text { Whiteness Perfect (FGM Dental Products, } \\
\text { Joinville, SC, Brazil) }\end{array}$ & $054 / 10$ & $\begin{array}{l}16 \% \text { carbamide peroxide, neutralized carbopol, potassium } \\
\text { nitrate, sodium fluoride, humectant (Glycol), deionized water }\end{array}$ \\
\hline MI Paste (GC Corporation, Tokyo, Japan) & 090406M & $\begin{array}{l}\text { Pure water, CPP-ACP, D-sorbitol, propylene glycol, silicon } \\
\text { dioxide, titanium dioxide, xylitol, phosphoric acid, flavoring, } \\
\text { zinc oxide, sodium saccharin, ethyl p-hydroxybezoate, } \\
\text { magnesium oxide, guar gum, propyl p- hydroxybezoate, butyl } \\
\text { p-hydroxybezoate }\end{array}$ \\
\hline $\begin{array}{l}\text { Artificial saliva (Farmafórmula, Natal, } \mathrm{RN} \text {, } \\
\text { Brazil) }\end{array}$ & - & $\begin{array}{l}\mathrm{K}_{2} \mathrm{KPO}_{4}, 70 \% \text { sorbitol, } \mathrm{NaF}, \mathrm{KCl}, \mathrm{NaCl}, \mathrm{MgCl}_{2} \cdot 6 \mathrm{H}_{2} 0 \text {, } \\
\text { Nipagin, Sodium Benzoate, Hydroxyethylcellulose }\end{array}$ \\
\hline
\end{tabular}

enamel without compromising bleaching potential. Moreover, Vasconcelos et al. [8] evidenced that the combination of MI and carbamide/hydrogen bleaching agents at different proportions did not affect tooth bleaching. However, the literature is scarce in studies evaluating mineral recovery, roughness and morphologic alterations of bleached enamel after bleaching teeth with the blend of MI and hydrogen peroxide. Moreover, it has not been evidenced if increased fractions of MI mixed with bleaching peroxides could increase the benefits regarding enamel properties of bleached enamel. Thus, the present study aimed to evaluate the impact of bleaching teeth using blends of a CPP-ACP paste (MI) and carbamide/hydrogen lowconcentration peroxides in different proportions on hardness, roughness and morphologic alterations of bleached enamel. The null hypothesis tested was that the associations between MI and peroxides do not affect enamel properties of bleached enamel.

\section{Materials and methods}

\section{Experimental design}

The factors under study were (1) bleaching protocols at nine levels: $7.5 \%$ hydrogen peroxide (HP) only, $16 \%$ carbamide peroxide (CP) only, MI only and blends of
$\mathrm{HP}$ or CP:MI at three proportions (1:1, 2:1, 1:2); and (2) evaluation periods at two levels: baseline (T0) and immediately after bleaching (T14). Manufacturers' data, chemical components and lot numbers of the materials used in this study are listed in Table I.

The experimental units consisted of 90 crowns of bovine incisors randomly assigned to nine groups $(n=10)$ (Table II).

\section{Specimens' preparation}

Ninety newly-extracted permanent bovine central incisors were selected and stored under refrigeration in a saturated thymol solution until preparation for testing. Teeth with any visible cracks or hypoplastic defects were excluded. The roots were sectioned $2 \mathrm{~mm}$ apically to the cemento-enamel junction using discarded double-face diamond disks (KG Sorensen, Barueri, Brazil). The entire crown went through a process of artificial staining [7-9]. A mixture (1:1) of 1 liter of red wine (Galiotto, Flores da Cunha, RS, Brazil) and black tea (Castellari, Guararema, SP, Brazil) was prepared. The tea solution was produced by boiling $2 \mathrm{~g}$ of tea leaves in $100 \mathrm{ml}$ of distilled water for $5 \mathrm{~min}$. The solution was filtered to separate the tea from the infusion. Each tooth was immersed in $10 \mathrm{ml}$ of the staining solution for 7.5 days at $37^{\circ} \mathrm{C}$.

Table II. Experimental groups.

\begin{tabular}{lll}
\hline Group & Proportion of peroxide: MI paste & Time of application per day \\
\hline HP-only & $1: 0=7.5 \% \mathrm{HP}(3 \mathrm{ml}):$ Without CPP-ACP & $60 \mathrm{~min}$ \\
$\mathrm{HP}(1: 1)$ & $1: 1=7.5 \% \mathrm{HP}(1.5 \mathrm{ml}):$ CPP-ACP $(1.5 \mathrm{ml})$ & $60 \mathrm{~min}$ \\
$\mathrm{HP}(2: 1)$ & $2: 1=7.5 \% \mathrm{HP}(2 \mathrm{ml}):$ CPP-ACP $(1 \mathrm{ml})$ & $60 \mathrm{~min}$ \\
$\mathrm{HP}(1: 2)$ & $1: 2=7.5 \% \mathrm{HP}(1 \mathrm{ml}):$ CPP-ACP $(2 \mathrm{ml})$ & $60 \mathrm{~min}$ \\
$\mathrm{CP}-$ only & $1: 0=16 \% \mathrm{CP}(3 \mathrm{ml}):$ Without CPP-ACP & $4 \mathrm{~h}$ \\
$\mathrm{CP}(1: 1)$ & $1: 1=16 \% \mathrm{CP}(1.5 \mathrm{ml}): \mathrm{CPP}-\mathrm{ACP}(1.5 \mathrm{ml})$ & $4 \mathrm{~h}$ \\
$\mathrm{CP}(2: 1)$ & $2: 1=16 \% \mathrm{CP}(2 \mathrm{ml}): \mathrm{CPP}-\mathrm{ACP}(1 \mathrm{ml})$ & $4 \mathrm{~h}$ \\
$\mathrm{CP}(1: 2)$ & $1: 2=16 \% \mathrm{CP}(1 \mathrm{ml}): \mathrm{CPP}-\mathrm{ACP}(2 \mathrm{ml})$ & $4 \mathrm{~h}$ \\
$\mathrm{CPP}-\mathrm{ACP}-$ only & $0: 1=$ Without Bleaching Agent: CPP-ACP $(3 \mathrm{ml})$ & $2 \mathrm{~min}$
\end{tabular}

$\mathrm{PH}$, hydrogen peroxide; CP, carbamide peroxide; CPP-ACP, MI paste containing casein phosphopeptide-amorphous calcium of phosphate. 
After staining, the specimens were positioned in a plastic mold and embedded using a self-curing polystyrene resin (Piraglass, Piracicaba, SP, Brazil). The enamel surfaces of the crowns were ground into a flat surface using SiC paper-grits \#120, \#320 and $\# 400$ and then polished with \#600, \#1200 and \#2400-grit aluminum oxide abrasive papers together with a $0.1 \mu \mathrm{m}$ alumina polishing suspension (Panambra, São Paulo, SP, Brazil). These steps were carried out on a polishing machine (APL-4, Arotec, São Paulo, SP, Brazil), exposing a $10 \mathrm{~mm}$ diameter of the enamel. In between the stages of wear/polishing, the samples were taken to an ultrasonic cleaner (Ultrasonic Cleaner, Odontobrás, São Paulo, SP, Brazil) for $5 \mathrm{~min}$.

\section{Initial hardness analysis (TO)}

The enamel hardness determination was performed with a microhardness tester (Pantec HSV 100A, Panambra, São Paulo, SP, Brazil) fitted with a $300 \mathrm{~g}$ load, which was used to make indentations on the enamel surface. The loaded diamond was allowed to sink and rest on the enamel surface for $10 \mathrm{~s}$ and the Vickers hardness number was determined. Three indentations were performed on the central area of each specimen, with the distance of $100 \mu \mathrm{m}$ between them, and then they were averaged.

\section{Initial roughness analysis (TO)}

The average surface roughness $(\mathrm{Ra})$ was measured at baseline and at post-bleaching time points. The roughness tester (Surtronic 25, Taylor-Hobson, Leicester, UK) is a highly sensitive device with a diamond point that scans the surface, connected to a unit that processes the information in a quantitative manner. Five readings were obtained in random directions (cut-off of $0.25 \mathrm{~mm}$ and speed of $0.1 \mathrm{~mm} / \mathrm{s}$ ).

\section{Bleaching procedures}

The bleaching treatment was performed over 14 days according to the manufacturer's instructions. For each specimen, a tray was fabricated using lowdensity polyethylene plates (FGM, Joinville, SC, Brazil) in a vacuum plasticizer (Plastivac P7, Bioart, São Carlos, SP, Brazil). The blends (Table II) were prepared freshly by mixing the bleaching gel (HP or $\mathrm{CP}$ ) with the CPP-ACP paste until obtaining an homogeneous paste which was loaded into a $3 \mathrm{ml}$ syringe (Embramac, Itajaí, SC, Brazil). Also, both the peroxides and the CPP-ACP paste alone were loaded into $3 \mathrm{ml}$ syringes. The content of each syringe was used to bleach the teeth during 7 days, so that mixtures had to be replenished.
A volume of $0.04 \mathrm{ml}$ of each bleaching agent was applied daily on the enamel surface. The individual mold was positioned onto each specimen and stored in a recipient containing artificial saliva at $37^{\circ} \mathrm{C}$. After $4 \mathrm{~h}$ for carbamide peroxide and $60 \mathrm{~min}$ for hydrogen peroxide, the gel was rinsed off the enamel surface with running distilled water for $15 \mathrm{~s}$. When not in contact with either bleaching agent, the specimens were kept immersed in artificial saliva at $37^{\circ} \mathrm{C}$. This medium was changed daily.

Final hardness and roughness analyses (T14)

Immediately after bleaching, other Vickers hardness and roughness measurements were taken in the samples following experimental conditions similar to those used at baseline.

\section{Scanning electron microscopy (SEM) analysis}

After bleaching protocols three non-bleached samples and three specimens of each group were randomly selected and analyzed under SEM (SSX-550, Shimadzu, Japan). The specimens were dried, fixed in aluminum stubs and then sputter-coated with gold-palladium for $4 \mathrm{~min}$. The surface morphology of enamel was examined at $3000 \times$ magnification. The superficial morphology of treated and untreated enamel was scored as follows, based on Ferreira et al. [10]: enamel presenting smooth surface with a few scratches; enamel surface presenting slight irregularities; enamel surface presenting moderate irregularities; enamel surface presenting accentuated irregularities; enamel surface presenting low deposition of granular structures; and enamel surface presenting accentuated deposition of granular structures.

\section{pH of the bleaching agents}

The $\mathrm{pH}$ of peroxides and mixtures was monitored on each of the 7 days through a $\mathrm{pH}$ meter (Digimed DM-20, Digicrom Analítica Ltda, São Paulo, SP, Brazil) with an electrode (Digimed DME-CVS) that was calibrated using $\mathrm{pH} 4.01$ and 6.86 solutions, respectively, before analysis. Three samples of each material were analyzed per day.

\section{Statistical analysis}

Hardness, roughness and $\mathrm{pH}$ data were analyzed by two-way ANOVA for repeated measurements and Tukey's test. All tests were performed using the SigmaStat 5 Software (SigmaStat, Windows Version 5.03, Copyrite ${ }^{\odot}$ Systat Software, Inc., Germany) at a pre-set significance level of 5\%. SEM images were descriptively analyzed. 


\section{Results}

\section{Hardness data}

ANOVA showed statistically significant differences for 'bleaching protocols' $(p<0.01)$, for 'evaluation period' $(p<0.01)$ and in the interaction 'bleaching protocols' $x$ 'evaluation period' $(p<0.01)$. Multiple comparisons are shown in Table III. No differences were found among the groups at T0 (baseline). After bleaching (T14), most of samples bleached with blends of MI presented increased hardness, except for the HP (1:2) group which presented statistically similar hardness means at T0 and T14. Samples bleached with peroxides only also showed similar hardness means at T0 and T14. At T14, the highest hardness mean was achieved by the application of MI (CPP-ACP-only group) and the application of CP only (CP-only group) provided the lowest hardness mean. Increased fraction of $\mathrm{MI}$ in peroxides/MI blends did not provided increased hardness means.

\section{Roughness data}

ANOVA showed statistically significant differences for 'bleaching protocols' $(p=0.04)$, for 'evaluation periods' $(p<0.01)$ and in the interaction 'bleaching protocols' $\times$ 'evaluation period' $(p<0.01)$. Multiple comparisons are shown in Table IV. No differences were found among the groups at T0 (baseline). After bleaching (T14), roughness means increased in HP (1:2), CP-only and CPP-ACP-only groups. At T14, the statistically highest roughness means were achieved by HP (1:2), CP-only, CP (1:1), CP $(2: 1)$ and CPP-ACP-only groups, while the statistically lowest roughness means were in the CP (1:2) group.

Table III. Means (standard-deviation) of hardness values according to the bleaching peroxides and evaluation periods tested.

\begin{tabular}{lll}
\hline & \multicolumn{2}{c}{ Evaluation periods } \\
\cline { 2 - 3 } Groups & T0 & T14 \\
\hline HP-only & $292.33(35.27)^{\mathrm{aA}}$ & $306.92(36.1)^{\mathrm{cdA}}$ \\
HP $(1: 1)$ & $276.38(40.80)^{\mathrm{aB}}$ & $321.83(39.7)^{\mathrm{bcA}}$ \\
HP (2:1) & $287.44(36.91)^{\mathrm{aB}}$ & $360.18(35.36)^{\mathrm{abA}}$ \\
HP $(1: 2)$ & $298.81(38.66)^{\mathrm{aA}}$ & $305.21(37.98)^{\mathrm{cdA}}$ \\
CP-only & $268.37(32.77)^{\mathrm{aA}}$ & $261.71(31.78)^{\mathrm{dA}}$ \\
CP $(1: 1)$ & $276.92(33.83)^{\mathrm{aB}}$ & $332.14(31.45)^{\mathrm{bcA}}$ \\
CP $(2: 1)$ & $286.81(39.85)^{\mathrm{aB}}$ & $363.54(37.82)^{\mathrm{abA}}$ \\
CP $(1: 2)$ & $287.71(39.92)^{\mathrm{aB}}$ & $329.63(35.74)^{\mathrm{bcA}}$ \\
CPP-ACP-only & $281.33(38.97)^{\mathrm{aB}}$ & $392.88(40.55)^{\mathrm{aA}}$ \\
\hline
\end{tabular}

Means followed by different letters, lowercase letters in the comparisons between lines and capital letters in the comparison between columns differ at 5\% significance level.

\section{Scanning electron microscopy (SEM) analysis}

Non-bleached samples presented a smooth surface with a few scratches (Figure 1). The samples of HPonly, HP (1:1), HP (2:1) and CP (1:2) groups revealed slight morphological alterations characterized by small irregularities (Figure 2). Moderate and accentuated superficial alterations were found in $\mathrm{CP}$ 2:1 and CP-only, respectively (Figures 3 and 4), which were characterized by depressions, porosities and superficial irregularities. The samples in the HP (1:2) and CP (1:1) groups presented images showing superficial deposition of granular structures (Figure 5), while the surface morphology of enamel that received CPP-ACP only (CPP-ACP-only group) was characterized by accentuated deposition of granular structures (Figure 6).

\section{pH of the bleaching agents}

The nine bleaching agents presented statistically similar $\mathrm{pH}$ means ranging from 6.8-7.0.

\section{Discussion}

The null hypothesis tested in this investigation was not validated because the concurrent application of the CPP-ACP paste and peroxides positively influenced on hardness, roughness and morphology of the bleached enamel. This confirms the benefits of associating a CPP-ACP paste to bleaching peroxides and suggests a novel safety at-home tooth bleaching technique.

It is known that the oxide-reduction reaction of the bleaching agent could lead to the dissolution of the organic and inorganic dental matrix until only carbon dioxide and water remain [2]. Although enamel remineralization is anticipated by the action of saliva during the bleaching, several in situ studies $[2,11,12]$ have reported a decrease in hardness of bleached enamel. A hardness loss could classically be related to mineral content loss resulting from demineralization [13]; therefore, the microhardness test is often applied to evaluate the adverse effects of bleaching agents on enamel [14].

To overcome mineral loss, different bleaching peroxide formulations have been developed and the addition of fluoride and calcium to agents has been studied by some investigators, obtaining potential interesting effects in regards to microhardness recovery during tooth bleaching $[15,16]$. It is likely that, during bleaching, enamel can become undersaturated compared with the gel and ionic balance occurs [17], leading to enamel ion uptake. To compensate for this, manufacturers add fluoride or calcium ions to bleaching agents, such as those agents used in this investigation. However, bleaching agents with low concentrations of peroxides might result in a change of phosphate besides the calcium and fluoride 
Table IV. Means (Ra) (standard-deviation) of roughness according to the bleaching peroxides and evaluation periods tested.

\begin{tabular}{lll}
\hline & \multicolumn{2}{c}{ Evaluation periods } \\
\cline { 2 - 3 } Groups & T0 & T14 \\
\hline HP-only & $0.067(0.007)^{\mathrm{aA}}$ & $0.073(0.007)^{\mathrm{bcA}}$ \\
HP $(1: 1)$ & $0.062(0.006)^{\mathrm{aA}}$ & $0.072(0.009)^{\mathrm{bcA}}$ \\
HP $(2: 1)$ & $0.056(0.013)^{\mathrm{aA}}$ & $0.067(0.006)^{\mathrm{bcA}}$ \\
HP $(1: 2)$ & $0.062(0.008)^{\mathrm{aB}}$ & $0.078(0.012)^{\mathrm{abA}}$ \\
CP-only & $0.056(0.010)^{\mathrm{aB}}$ & $0.072(0.017)^{\mathrm{abA}}$ \\
CP $(1: 1)$ & $0.066(0.021)^{\mathrm{aA}}$ & $0.074(0.016)^{\mathrm{abA}}$ \\
$\mathrm{CP}(2: 1)$ & $0.071(0.015)^{\mathrm{aA}}$ & $0.082(0.017)^{\mathrm{abA}}$ \\
CP $(1: 2)$ & $0.055(0.011)^{\mathrm{aA}}$ & $0.064(0.013)^{\mathrm{cA}}$ \\
CPP-ACP-only & $0.058(0.011)^{\mathrm{aB}}$ & $0.073(0.013)^{\mathrm{abA}}$ \\
\hline
\end{tabular}

Means followed by different letters, lowercase letters in the comparisons between lines and capital letters in the comparison between columns differ at $5 \%$ significance level.

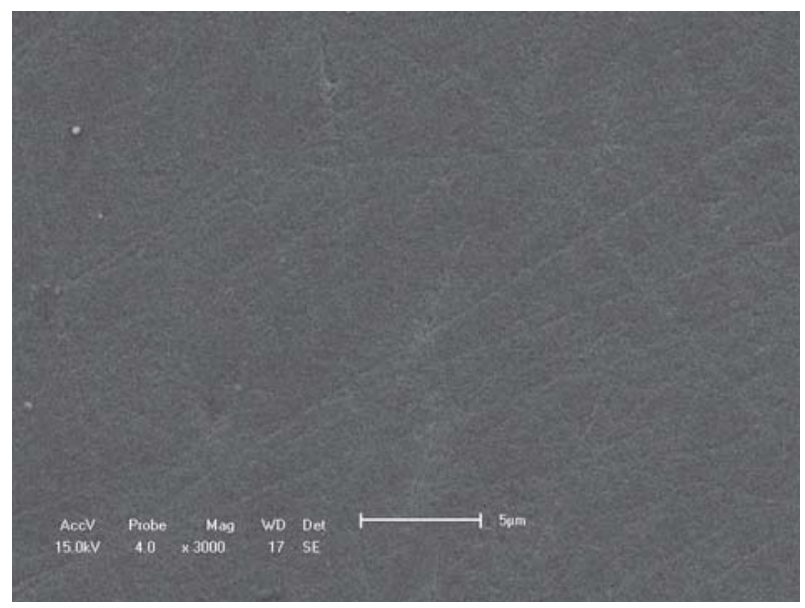

Figure 1. Enamel presenting smooth surface with a few scratches.

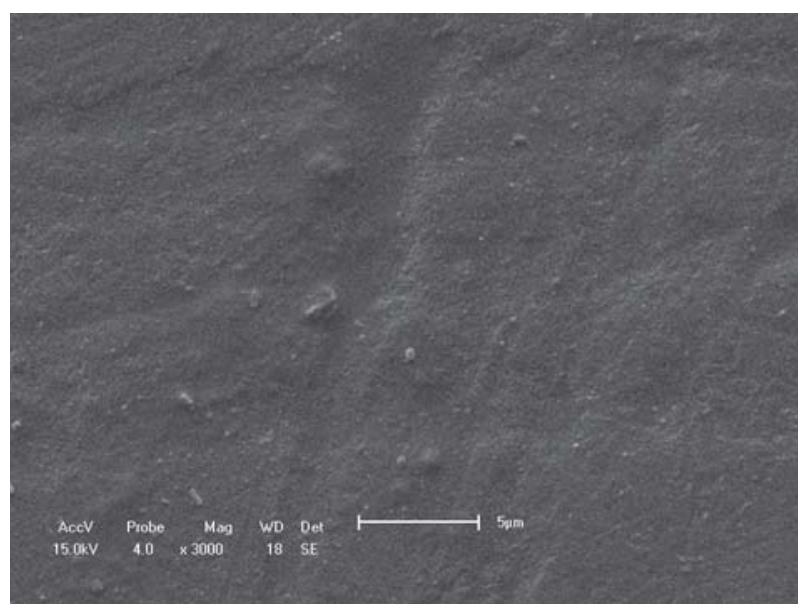

Figure 2. Enamel surface presenting slight irregularities.

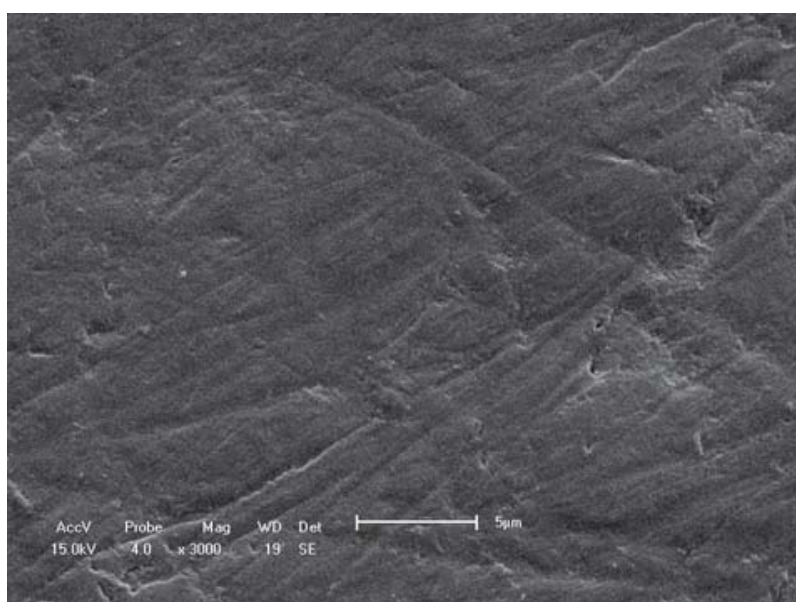

Figure 3. Enamel surface presenting moderate irregularities.

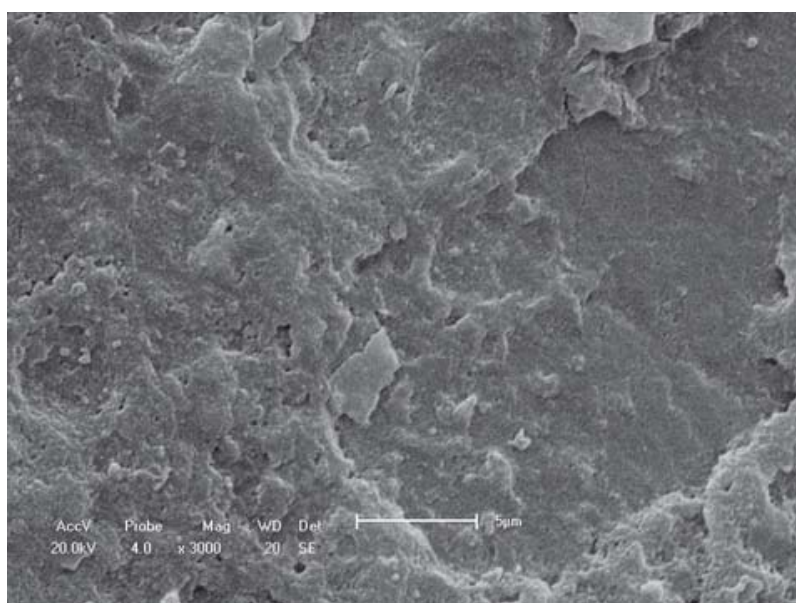

Figure 4. Enamel surface presenting accentuated morphological alterations.

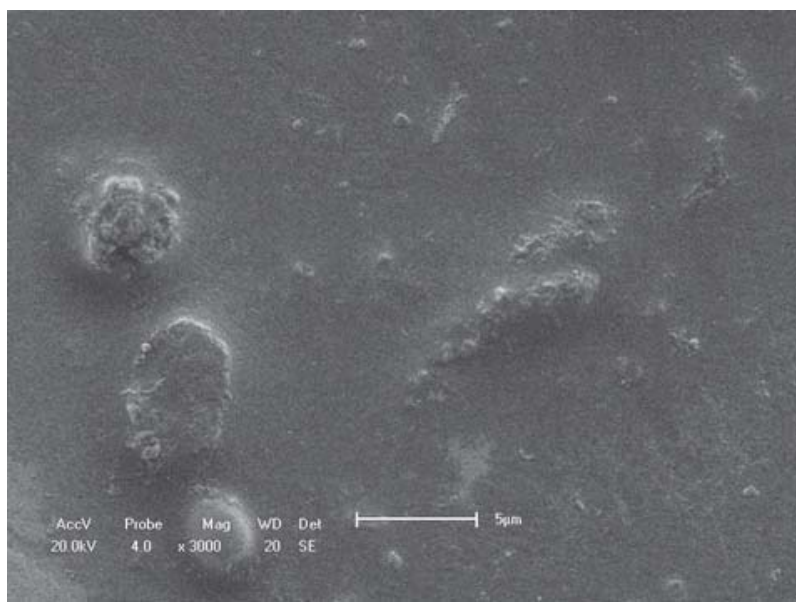

Figure 5. Enamel surface presenting low deposition of granular structures. 


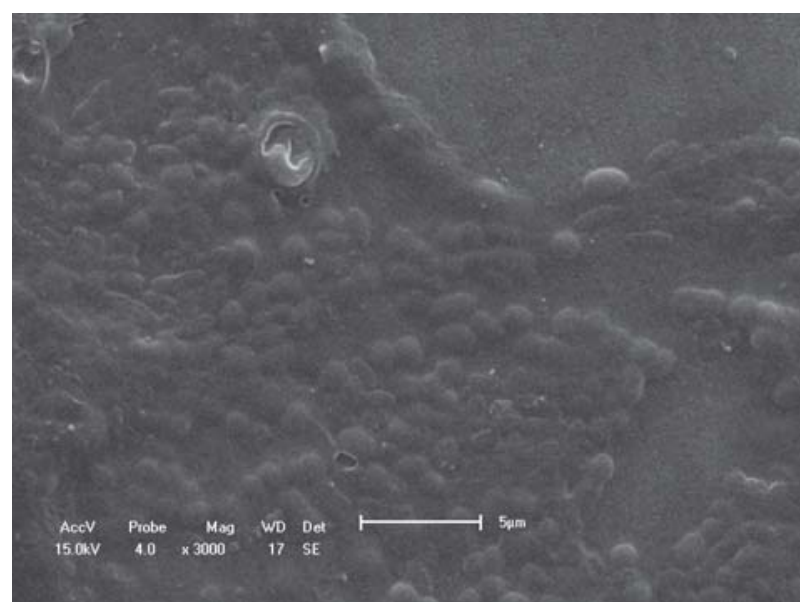

Figure 6. Enamel surface presenting accentuated deposition of granular structures.

content of enamel [4]. Thus, a remineralization system should also supply phosphate because this mineral may be lost after bleaching. Some peroxide agents (NightWhite ACP/ACFP, Discus Dental, Culver City, CA) containing an unstabilized ACP/ACFP system might be commercially available. It has been shown that gels containing ACP affected remineralization patterns of pre-demineralized bovine enamel better than fluoridated (sodium fluoride) bleaching agents [18]. However, the ACP system stabilized by $\mathrm{CPP}$, otherwise known as $\mathrm{CPP}-\mathrm{ACP}$, provides a higher reservoir of bioavailable calcium and phosphate ions in comparison with ACP only, leading to an increased remineralization potential [19]. Although a large body of scientific evidence demonstrates that CPP-ACP could promote the remineralization of even enamel sub-surface caries lesions [19], this study is the first to analyze the effect of several fractions of MI paste in conjunction with carbamide and hydrogen peroxides on bleached enamel microhardness. The increased post-bleaching microhardness for samples bleached using both peroxides and MI suggest a mineral deposition on enamel. It is likely that this mineral gain was also favored by the synergist effect of fluoride contained in the peroxides with CPP-ACP on enamel remineralization, as observed elsewhere [20]. On the other hand, it was noticed that blends with higher fractions of MI did not provided superior hardness recovery in comparison with other blends. This may be due to the fact that a lower fraction of $\mathrm{MI}$ is probably necessary to provide the highest level of ions uptake. Nevertheless, further chemical analysis might be performed in an attempt to confirm this presumption.

It has been observed that carbopol was able to cause a continuing demineralization of enamel and dentin, even at neutral $\mathrm{pH}$ [21]. Thus, the presence of fluoride and/or calcium in these bleaching peroxides was probably able to slightly recover mineral loss caused by the carbopol, maintaining hardness of bleached enamel similar to those of non-bleached enamel. However, the blend of HP/MI (1:2) was not capable of providing increased hardness of bleached enamel. It is likely that the low fraction of HP might not have caused an undersaturation sufficient to stimulate the enamel to absorb a high quantity of ions. Further chemical analysis might be performed to clarify this hypothesis.

Most of the groups achieved statistically similar roughness means at $\mathrm{T} 0$ and $\mathrm{T} 14$ due to mineral recovery during bleaching, as confirmed by hardness and morphology data. However, it could be perceived that increased roughness means in the HP (1:2) and CPP-ACP-only groups was due to mineral deposition on the enamel surface, as observed by SEM images and hardness data. On the other hand, increased hardness for the CP-only group could be attributed to accentuated irregularities generated by the peroxide which was observed by SEM. In this case, increased roughness due to the deposition of CPPACP cannot be seen as a negative side-effect due to benefits provided by the presence of CPP-ACP on dental tissues. These finding highlight the importance to characterize superficial morphological changes on dental structures by enhanced bleaching peroxides using roughness test and SEM images. By means of images, the occurrence of increased roughness can be attributed to the mineral deposition or to the presence of irregularities/depressions.

The fact that irregularities/depressions and increased roughness were observed only for samples bleached with carbamide peroxide (CP-only), in comparison with HP-only, can be attributed to the urea release by carbamide peroxides [22]. It has been known for a long time that urea is capable of attacking protein structures by dissociation $\mathrm{H}$-bond between $\mathrm{CO}$ and $\mathrm{NH}$ groups [23]. Thus, the urea released from carbamide peroxides influence upon surface morphological changes, as observed in the $\mathrm{CP}$-only group.

Overall, the results obtained in the present investigation are of great concern to decrease early sideeffects caused by at-home bleaching peroxides, corroborating preliminary data obtained in vivo when teeth were bleached with a blend of $\mathrm{CP} / \mathrm{MI}$ in $1: 1$ proportion [24]. However, further clinical trials should be performed in an attempt to confirm the findings obtained in this laboratory investigation.

Within the limitations of this in vitro study, the mixture of a paste containing CPP-ACP to the athome bleaching agents was able to prevent negative changes of hardness, roughness and morphology on bleached enamel. However, higher fractions of the paste containing CPP-ACP did not offer increased benefits in comparison with reduced fractions.

\section{Acknowledgments}

The authors thank FGM (Joinville, SC, Brazil), DFL (Rio de Janeiro, RJ, Brazil), GC Corporation (Tokyo, 
Japan) and Vigodent (Rio de Janeiro, RJ, Brazil) for providing some materials used in this study.

Declaration of interest: The authors report no conflicts of interest. The authors alone are responsible for the content and writing of the paper.

\section{References}

[1] Giachetti L, Bertini F, Bambi C, Nieri M, Scaminaci Russo D. A randomized clinical trial comparing at-home and in-office tooth whitening techniques: a ninemonth follow-up. J Am Dent Assoc 2010;141:1357-64.

[2] Soldani P, Amaral CM, Rodrigues JA. Microhardness evaluation of in situ vital bleaching and thickening agents on human dental enamel. Int J Periodontics Rest Dent 2010; 30:203-11.

[3] Araújo EM, Baratieri LN, Vieira LC, Ritter AV. In situ effect of $10 \%$ carbamide peroxide on microhardness of human enamel: function of time. J Esthet Restor Dent 2003;15: 166-73.

[4] Efeoglu N, Wood D, Efeoglu C. Microcomputerised tomography evaluation of $10 \%$ carbamide peroxide applied to enamel. J Dent 2005;33:561-7.

[5] Reynolds E. Casein phosphopeptide-amorphous calcium phosphate: the scientific evidence. Adv Dent Res 2009;21: 25-9.

[6] Manton DJ, Walker GD, Cai F, Cochrane NJ, Shen P, Reynolds EC. Remineralization of enamel subsurface lesions in situ by the use of three commercially available sugar-free gums. Int J Paediatr Dent 2008;18:284-90.

[7] Borges BC, Borges JS, Melo CD, Pinheiro IV, dos Santos AJ, Braz R, et al. Efficacy of a novel at-home bleaching technique with carbamide peroxides modified by CPP-ACP and its effect on the microhardness of bleached enamel. Oper Dent 2011; 36:521-8.

[8] Vasconcelos AA, Cunha AG, Borges BC, Machado CT, Santos AJ. Tooth whitening with hydrogen/carbamide peroxides in association with a CPP-ACP paste at different proportions. Aust Dent J 2011; in press.

[9] Kielbassa AM, Beheim-Schwarzbach NJ, Neumann K, Nat R, Zantner C. In vitro comparison of visual and computer-aided pre- and post-tooth shade determination using various home bleaching procedures. J Prosthet Dent 2009;101:92-101.

[10] Ferreira SS, Araújo JL, Morhy ON, Tapety CM, Youssef MN, Sobral MA. The effect of fluoride therapies on the morphology of bleached human dental enamel. Microsc Res Tech 2011;74:512-16.
[11] Rodrigues JA, Marchi GM, Ambrosano GM, Heymann HO, Pimenta LA. Microhardness evaluation of in situ vital bleaching on human dental enamel using a novel study design. Dent Mater 2005;21:1059-67.

[12] Basting RT, Rodrigues-Júnior AL, Serra MC. The effect of $10 \%$ carbamide peroxide bleaching material on microhardness of sound and demineralized enamel and dentin in situ. Oper Dent 2001;26:531-9.

[13] Featherstone JD, ten Cate M, Shariati M, Arends J. Comparison of artificial caries-like lesions by quantitative microradiography and microhardness profiles. Caries Res 1983;17: 385-91.

[14] Attin T, Schmidin PR, Wegehaupt F, Wiegand A. Influence of study design on the impact of bleaching agents on dental enamel microhardness: a review. J Dent 2009;25:143-57.

[15] Cavalli V, Rodrigues LK, Paes-Leme AF, Brancalion ML, Arruda MA, Berger SB, et al. Effects of bleaching agents containing fluoride and calcium on human enamel. Quintessence Int 2010;41:157-65e.

[16] Attin T, Betke H, Schippan F, Wiegand A. Potential of fluoridated carbamide peroxide gels to support post-bleaching enamel re-hardening. J Dent 2007;35:755-9.

[17] Gao XJ, Elliott JC, Anderson P. Scanning and contact microradiographic study of the effect of degree of saturation on the rate of enamel demineralization. J Dent Res 1991;70:1332-7.

[18] Tschoppe P, Neumann K, Mueller J, Kielbassa AM. Effect of fluoridated bleaching gels on remineralization of predemineralized bovine enamel in vitro. J Dent 2009;37:156-62.

[19] Cochrane NJ, Cai F, Huq NL, Burrow MF, Reynolds EC. New approaches to enhanced remineralization of tooth enamel. J Dent Res 2010;89:1187-97.

[20] Srinivasan N, Kavitha M, Loganathan SC. Comparison of the remineralization potential of CPP-ACP and CPP-ACP with 900 ppm fluoride on eroded human enamel: an in situ study. Arch Oral Biol 2010;55:541-4.

[21] Basting RT, Rodrigues AL Jr, Serra MC. The effect of $10 \%$ carbamide peroxide, carbopol and/or glycerin on enamel and dentin microhardness. Oper Dent 2005;30:608-16.

[22] Sasaki RT, Arcanjo AJ, Flório FM, Basting RT. Micromorphology and microhardness of enamel after treatment with home-use bleaching agents containing $10 \%$ carbamide peroxide and 7.5\% hydrogen peroxide. J Appl Oral Sci 2009;17: 611-16.

[23] Arends J, Jongebloed WL, Goldberg M, Schuthof J. Interaction of urea and human enamel. Caries Res 1997;26:531-9.

[24] Borges BC, Vasconcelos AA, Cunha AG, Pinheiro FH, Machado CT, Santos AJ. Preliminary clinical reports of a novel night-guard tooth bleaching technique modified by casein phosphopeptide-amorphous calcium phosphate (CPP-ACP). Eur J Esthet Dent 2011;6:446-53. 
Copyright of Acta Odontologica Scandinavica is the property of Taylor \& Francis Ltd and its content may not be copied or emailed to multiple sites or posted to a listserv without the copyright holder's express written permission. However, users may print, download, or email articles for individual use. 